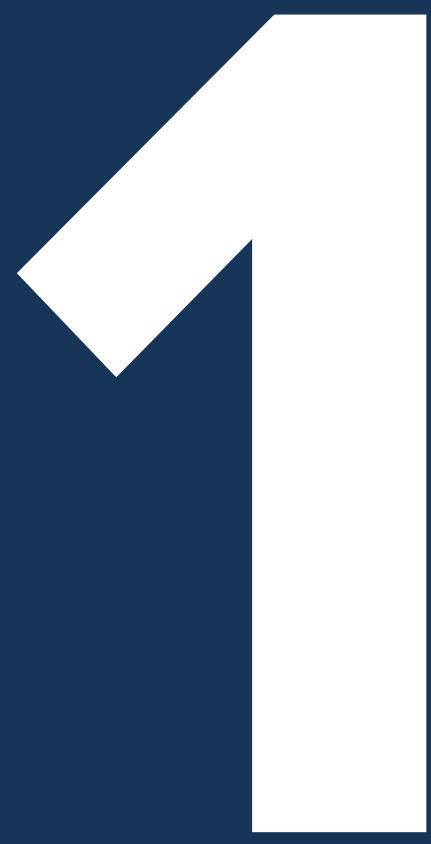

- - -

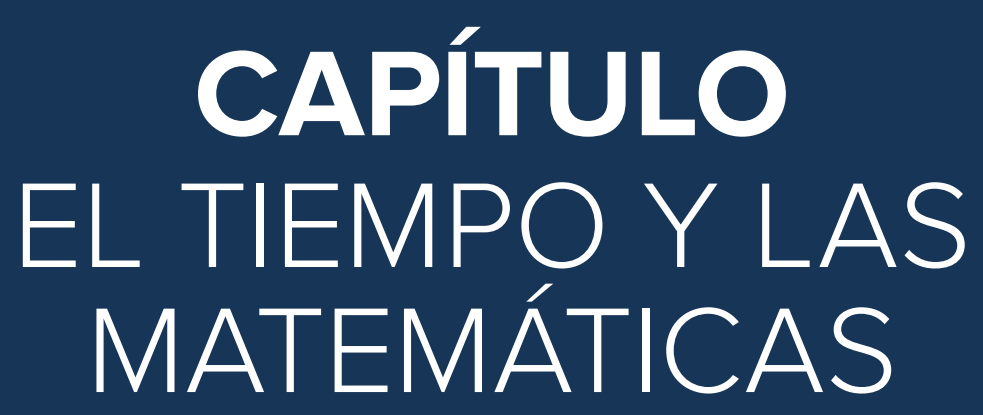




\section{Guía práctica para entender por qué el tiempo es tan importante en la gestión de un negocio y cómo afecta decisiones de inversión basadas en el valor del dinero durante el tiempo; en este capítulo el empresario recordará lo relacionado con las tasas de interés y cómo la periodicidad es tan importante para su correcta interpretación.}

García, Johann \& Maldonado, Cristian

\section{UNA INTRODUCCIÓN: ¿QUÉ SE ENTIENDE POR DINERO?}

A lo largo de la historia el hombre ha empleado diferentes objetos: metales o elementos como representación de dinero o moneda, con el fin de facilitar los intercambios que demandan la satisfacción de sus necesidades básicas. Inicialmente se presentaban incipientes formas de intercambio (trueque), hasta hoy donde se propugna por un menor uso del dinero en su forma física a cambio de utilizar diferentes medios de pagos electrónicos.
Independientemente de las condiciones económicas, del entorno, de los países y de otras consideraciones, la mayoría de las personas y empresas usan de manera frecuente dinero para comprar o vender productos y/o servicios, para pagar una obligación o por concepto de ingresos, por lo que se observa que el dinero es fundamental para el funcionamiento de la economía.

No obstante, ante la relevancia que tiene el dinero, no existe una definición única y su concepto depende de las funciones para las que esté destinado, así: 
»El dinero como depósito de valor, es decir, se espera que su valor se mantenga de una manera presumible a lo largo del tiempo; un ejemplo típico es el caso de los metales preciosos, oro y plata. Sin embargo, el poder adquisitivo del dinero (es decir, la cantidad de bienes y servicios que se pueden comprar con una cantidad determinada de dinero) no es constante, y en condiciones inflacionarias el uso del medio de intercambio como reserva de poder adquisitivo implica una pérdida real del mismo. Por ejemplo, si se atesora $\$ 1.000 .000$ en efectivo durante un año, se estaría exponiendo esta cantidad de dinero a una pérdida de poder adquisitivo ya que por efecto del aumento del nivel de precios de una economía, la cantidad de bienes que se pueden adquirir con esta suma de dinero es, a lo largo del tiempo, cada vez menor. Esta situación implica un dilema para el individuo ya que el valor del dinero podría deteriorarse más rápidamente que otros activos alternativos (acciones, metales preciosos, etc.), pero el uso de esos activos como reserva de poder adquisitivo significa un sacrificio de liquidez.
»El dinero como unidad de cuenta, determina el precio de los productos, o servicios, o como la unidad en términos de la cual se expresan los valores de los demás bienes y servicios; también es la unidad usada para medir y comparar la riqueza.

Como medio de cambio, lo cual facilita y permite el intercambio para adquirir productos o servicios, pagar obligaciones u otros fines, es decir, se refiere al hecho de mantenerlo porque piensa intercambiarse por otra cosa, en vez de desearlo por sí mismo, lo cual se traduce en reducción del tiempo y simplifica las transacciones. Como lo menciona Cole (2014, pág. 1) "permite que el intercambio se lleve a cabo lo más económicamente posible a fin de facilitar el grado óptimo de especialización, con el correspondiente aumento en la productividad", de ahí que el dinero es un determinante fundamental en su utilidad como medio de intercambio, al tener una aceptabilidad por cualquier agente económico. 
Keynes (1965) en su Teoría General de la Ocupación, el Interés y el Dinero, menciona un aspecto importante para considerar: ¿cuál es la recompensa que obtienen las personas de preferir dinero líquido, sacrificando el consumo actual? La respuesta bastante simple, pero de gran transcendencia hace referencia a un concepto fundamental en las finanzas y en el mundo de los negocios en general: la tasa de interés, puesto que el dinero en efectivo (papel moneda) no gana interés y por el contrario puede perder poder adquisitivo al tener menos capacidad de compra ante un incremento en el nivel de los precios (inflación). En el contexto actual, es posible afirmar que el precio del dinero es la tasa de interés y como cualquier otro producto, en la medida que exista mayor cantidad de dinero en la economía, el precio tiende a bajar y viceversa (ceteris paribus).

En el mercado financiero existe la oferta y demanda de recursos con pretensiones opuestas, es así como quienes demandan dinero (prestatarios), ante un incremento en la tasa de interés, estarán dispuestos a solicitar menos créditos (mayor costo de financiamiento). De otra parte, los oferentes (inversionistas), estarán dispuestos a llevar sus recursos para obtener mayores ingresos (rendimientos financieros). El caso contrario se presenta cuando la tasa de interés baja, las personas y empresas estarán dispuestas a solicitar más créditos (menor costo financiero), no obstante, a quienes tengan excedentes de recursos no les es atractivo invertir dados los bajos ingresos (vía menores intereses) y no compensa el sacrificio de dejar de consumir en el presente.

\section{VALOR DEL DINERO EN EL TIEMPO}

Seguramente la anterior introducción le habrá permitido al lector familiarizarse con la situación de que las personas no son indiferentes al hecho de recibir una cantidad de dinero hoy, a recibir esa misma cantidad de dinero en el futuro (ya sea dentro de un mes, un año, etc.). Normalmente, se tendrá una preferencia por el consumo actual y debe haber algún incentivo para sacrificarlo por consumo futuro. Esta preferencia es resultado de dife- 
rentes hechos económicos relacionados, tales como el aumento del nivel de precios de la economía (inflación), la incertidumbre del futuro, y el costo de oportunidad, entre otros. A continuación, se explican brevemente estos conceptos:

» La inflación es entendida como el aumento del nivel general de precios de la economía, esto quiere decir que, por distintos factores tanto internos como externos (aumento del precio de las materias primas, de las importaciones, etc.), los precios que pagan los consumidores finales por los diferentes bienes y servicios de la economía aumentan con el paso del tiempo (recuerde el lector cuánto le costaba un pasaje de transporte público en su adolescencia y compárelo con el precio actual).

» Incertidumbre y riesgo: ya lo dice el adagio popular: más vale pájaro en mano, que cien volando, y este es un principio que rige la conducta de la mayoría de las personas. En general, los seres humanos son adversos al ries- go y muchas de las transacciones económicas que se hacen implican algún grado de riesgo.

El costo de oportunidad: este término está asociado con el costo, ya sea monetario o no, explícito e implícito, de las decisiones que se toman. En el ámbito específico de las finanzas, se asocia con el hecho de que los recursos son finitos, mientras que las alternativas de inversión no lo son. En este sentido, al tomar una decisión, se está renunciando a los beneficios posibles de las alternativas que se excluyen, por tanto, siempre se optará por aquella alternativa que genere un mayor beneficio porque si se renuncia a esta el costo será mayor. Por ejemplo, si usted como empresario está acostumbrado a que sus negocios le generen una rentabilidad promedio del $20 \%$, no sería racional aceptar nuevas alternativas de inversión cuya rentabilidad sea inferior (por ejemplo, el 15\%) porque estaría comprometiendo recursos que podrían generar un mayor beneficio. Recuerde, "en economía no hay almuerzo gratis”. 
La variación entre la percepción de valor del dinero el día de hoy y cualquier momento en el futuro se puede expresar en términos porcentuales, como la tasa de interés. Cuando se analiza desde el punto de vista del inversionista, la tasa expresa la rentabilidad que se tiene por comprometer una cantidad de recursos en un activo o conjunto de activos (empresa, proyectos, activos financieros). Desde el punto de vista del prestatario, la tasa de interés representa el costo que debe pagar por el uso de los recursos que le están facilitando!.

De acuerdo con la forma como se capitaliza, es decir, si el cálculo del interés tiene en cuenta la variación del capital, se pueden encontrar la forma de interés simple e interés compuesto.
Para entender mejor esta diferenciación, imagine el lector la siguiente situación: usted deposita en una cuenta de ahorros, al inicio del año, la suma de $\$ 1.000 .000$ y no hace ningún retiro durante seis meses, la cuenta reconoce un interés del $1 \%$ cada mes. Veamos cómo funcionan los diferentes tipos de interés.

De acuerdo con la tabla 1, se observa que, mediante la modalidad de interés simple, los intereses siempre se calculan sobre la misma base o lo que es lo mismo que decir que los intereses no se capitalizan (no se convierten en capital). Por tanto, mediante esta modalidad estos siempre serán iguales, siempre y cuando no se modifique el capital sobre el que se calculan.

\footnotetext{
1. Usualmente, las tasas de interés que se encuentran en los diferentes productos financieros, específicamente productos de crédito reflejan diferentes factores relacionados con el riesgo, la oferta de recursos disponibles para préstamo, y la política monetaria del país. En Colombia, las instituciones financieras tienen la libertad de cobrar la tasa de interés que refleje sus costos administrativos y que además deje un margen de utilidad, teniendo en cuenta las variables antes mencionadas, siempre y cuando ésta no sobrepase el límite de usura establecido para el tipo de producto. La tasa de usura es la tasa máxima que por regulación pueden cobrar las instituciones financieras por los créditos desembolsados, incluyendo las tarjetas de crédito. En el país, la superintendencia reporta con distinta periodicidad de certificación la tasa de usura para el crédito de consumo y ordinario y también para los microcréditos, siendo ésta última más elevada dado el perfil de riesgo del mercado al que se encuentra dirigido.
} 


\section{TABLA 1}

\section{LIQUIDACIÓN DE INTERESES BAJO LA MODALIDAD SIMPLE Y COMPUESTA}

Fuente: Elaboración propia

\section{Interés simple}

Base sobre la

Tiempo que se calculan

los intereses
Capital acumulado al final del período

1

1.000 .000

10.000

1.010 .000

2

1.000 .000

10.000

1.020 .000

3

1.000 .000

10.000

1.030 .000

4

1.000 .000

10.000

1.040 .000

5

1.000 .000

10.000

1.050 .000

6

1.000 .000

10.000

1.060 .000 


\section{Interés compuesto}

Base sobre la

Tiempo

que se calculan

los intereses

Interés

Capital acumulado

al final del período

$\begin{array}{llll}1 & 1.000 .000 & 10.000 & 1.010 .000\end{array}$

2

1.010 .000

10.100

1.020 .100

3

1.020 .100

10.201

1.030 .301

4

1.030.301

10.303

1.040 .604

5

1.040 .604

10.406

1.051 .010

6

1.051 .010

10.510

1.061 .520

\subsection{0}

Por otra parte, el interés compuesto sí comprende la capitalización de los intereses, es decir, que éstos se convierten, al final de cada mes, en parte del capital sobre el cual se calcularán los intereses del mes siguiente. Por tanto, bajo esta modalidad la acumulación de intereses es mayor.
La situación es análoga al caso de un crédito en la modalidad de interés compuesto, los intereses pagados por una deuda serán cada vez menores en la medida en que parte de la cuota pagada sea destinada a disminuir el capital adeudado. 


\section{CASO DE ESTUDIO:}

\section{¿CUÁNTO CUESTA REALMENTE UN CRÉDITO CON UN "GOTA A GOTA"?}

En el contexto económico del país, el acceso a crédito formal a las micros, pequeñas y medianas empresas (mipymes) es, por diferentes causas, muy restringido. De acuerdo con la Asociación Colombiana de Pequeñas y Medianas Empresas (Acopi) el $62 \%$ de las mipymes no cuenta con acceso a fuentes formales de préstamos financieros que son claves para su permanencia y crecimiento (El Espectador, 2018). Esta situación obliga a este tipo de organizaciones a hacer uso del mercado extrabancario o agiotistas, también conocidos coloquialmente como préstamos gota a gota. Además de los riesgos a la seguridad de los empresarios que pueden representar estas fuentes de financiación, su costo financiero es muy elevado, toda vez que, en la mayoría de los casos, la liquidación de intereses se hace bajo la modalidad de interés simple, generalmente a una tasa mayor a la de usura, encareciendo el costo financiero para las empresas.

A manera ilustrativa se presenta un ejemplo, mediante el cual se realiza un paralelo entre los costos asumidos por los deudores en un préstamo a un año con una entidad financiera tradicional y cuando se acude a préstamos otorgados fuera del sistema financiero así: (ver tabla página 23)
Como se puede observar en este ejercicio, la diferencia es de $\$ 72.238$ de menor valor pagado en la deuda contraída en una entidad financiera con respecto al valor pagado en el mercado extrabancario. Además del beneficio económico obtenido, se pueden mencionar otros que los deudores consiguen en el sistema financiero: en la medida en que vayan cancelando oportunamente sus obligaciones, alcanzan mayor visibilidad ya que construyen historial crediticio, mejoran el perfil de riesgo, lo que se traduce en menores tasas para futuros créditos y mayores plazos y montos. Así mismo, en el caso de créditos que tengan seguro de vida para deudores, ante el fallecimiento del deudor o que éste presente incapacidad total y permanente, el seguro cubre la totalidad de la deuda con la entidad financiera.

Por último, en la medida que una mayor población acuda a entidades especializadas, tal como lo menciona Barona (2004, pág. 98) "se contribuye a que los esfuerzos de prestación de servicios financieros a los pobres y a los microempresarios tenga un mayor impacto en la reducción de la pobreza y a que las instituciones que atienden las necesidades financieras de estas 
poblaciones lo hagan de manera más eficaz y eficiente".

*Para fines ilustrativos se utiliza como referente la tasa de usura para un crédito Mipyme. Tener en cuenta que las tasas de interés cobradas en el mercado extrabancario son mucho más elevadas que las propuestas en este caso. Estas se si- túan entre el 10\% y el 20\% mensual, lo que en términos efectivos anuales (ver aparte de sección de la tasa de interés) se traduce a una tasa del $214 \%$ y del $792 \%$ respectivamente.

**este valor se obtiene aplicando la modalidad de interés simple, se invita al lector a verificar el resultado

Nota: NA: No aplica

Fuente: Elaboración propia

Entidad

Financiera

\begin{tabular}{lll}
\hline Valor préstamo & $\$ 1.000 .000$ & $\$ 1.000 .000$ \\
\hline Plazo (meses) & 12 & 12 \\
\hline $\begin{array}{l}\text { Tasa nominal } \\
\text { mes vencido }\end{array}$ & $3,40 \%$ & $3,40 \% *$ \\
\hline $\begin{array}{l}\text { Comisión ley } \\
\text { mipyme } 7.5 \%\end{array}$ & $\$ 75.000$ & NA \\
\hline IVA $19 \%$ & NA \\
\hline $\begin{array}{l}\text { Cuota fija } \\
\text { mensual* }\end{array}$ & $\$ 14.250$ & NA \\
\hline $\begin{array}{l}\text { Seguro vida } \\
\text { deudores }\end{array}$ & $\$ 102.876$ & NA \\
\hline $\begin{array}{l}\text { Valor total } \\
\text { intereses }\end{array}$ & $\$ 12.000$ & $\$ 408.000 * *$ \\
\hline
\end{tabular}

Mercado

Extrabancario

$\$ 1.000 .000$

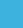




\section{EQUIVALENCIAS DE DINERO EN DIFERENTES HORIZONTES DE TIEMPO}

La comprensión del concepto de interés (como una medida de la variación del valor del dinero en el tiempo) permite que el lector se pueda relacionar con el concepto de equivalencias de dinero en el tiempo. La tabla 1 muestra que, sin importar la forma cómo se calculan los intereses, la cantidad de dinero inicial se transforma en una cantidad de dinero diferente en el futuro. Por tanto, si bien $\$ 1.000 .000$ y $\$ 1.061 .520$ (para interés compuesto) no son numéricamente iguales, en términos financieros se puede decir que son cantidades de dinero equivalentes, ya que sería indiferente recibir $\$ 1.000 .0000$ el día de hoy o recibir $\$ 1.061 .520$ dentro de seis meses, si la tasa de oportunidad fuera del $1 \%{ }^{2}$
La generalización de la operación matemática que se hace para obtener la equivalencia entre una suma de dinero el día de hoy y en el futuro, permite construir una de las ecuaciones en las que se fundamenta gran parte del análisis financiero y que posibilita hacer este cálculo para cualquier horizonte de tiempo:

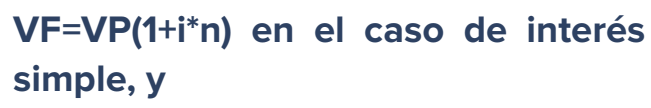

VF $=\mathrm{VP}\left(1+\mathrm{i}^{*} \mathrm{n}\right)$ en el caso de interés simple, $y$

\section{$\mathrm{VF}=\mathrm{VP}(1+\mathrm{i})^{\mathrm{n}}$ en el caso de interés compuesto}

Donde VF es el valor futuro equivalente a una cantidad de dinero presente, VP, la tasa de interés de la operación es $i$, y $\mathrm{n}$ representa el número de períodos. De esta fórmula se puede despejar cualquiera de las variables de interés y encontrarlas siempre y cuando se conozcan todas las demás: ${ }^{3}$

\footnotetext{
2. Si recibe el millón de pesos el día de hoy, usted lo podría invertir en sus alternativas normales de inversión, en este caso la cuenta de ahorros, y recibir dentro de seis meses $\$ 1.061 .520$ o lo que equivalente a no recibir nada el día de hoy sino $\$ 1.061 .520$ en seis meses.

3. Dado que el interés simple es de poco uso en el contexto de las finanzas, se presentan las fórmulas asociadas a este pero los ejemplos y los temas que se tocarán en las siguientes secciones del capítulo se basarán en el interés compuesto.
} 


\section{TABLA 2}

\section{FORMULAS BÁSICAS EQUIVALENCIAS \\ DE DINERO EN EL TIEMPO}

Fuente: Elaboración propia

Valor futuro (VF)

$V F=V P(1+i * n)$

$V F=V P(1+i)^{n}$

Valor presente (VP)

$V P=V F /(1+i * n)$

$V P=V F /(1+i)^{n}$

Tasa de interés

$$
\mathrm{i}=(\mathrm{VF}-\mathrm{VP}) /(\mathrm{VP} * \mathrm{n}) \quad \mathrm{i}=(\mathrm{VF} / \mathrm{VP})^{(1 / \mathrm{n})-1}
$$

Número de períodos

$$
n=(V F-V P) /(V P * i) \quad n=\log V F-\log V P / \log (1+i)
$$




\section{EJEMPLOS4:}

» Búsqueda del valor futuro: El día de hoy usted invierte $\$ 5.000 .000$ en un negocio de comidas, donde estima que la rentabilidad esperada del mismo será del $25 \%$ anual, usted quisiera saber en cuánto se convertirá el capital invertido al final de cinco años, teniendo en cuenta que reinvierte las ganancias que se generan cada año en el negocio:

Valor presente (VP): $\$ 5.000 .000$

Tasa de interés (i): 25\% anual

Tiempo de la operación (n): 5 años

Valor futuro (VF) =

$V F=V P(1+i)^{n}$

$V F=5.000 .000^{*}(1+25 \%)^{5}$

$V F=\$ 15.258 .789,06$
Por tanto, al final de cinco años, su capital se habrá transformado en $\$ 15.258 .789,06$.

\Búsqueda del valor presente: Al cabo de dos años usted estima que deberá renovar una máquina que le costará $\$ 7.000 .000$, si su negocio genera una rentabilidad del 2,1\% mensual, ¿cuánto deberá invertir el día de hoy para acumular la cantidad de dinero suficiente en el tiempo necesario?

$V F=\$ 7.000 .000$

$\mathrm{i}=2,1 \%$ mensual

$\mathrm{n}=24$

$V P=V F /(1+i)^{n}$

$\mathrm{VP}=\$ 7.000 .000 /(1+2,1 \%)^{24}$

$=\$ 4.250 .893,55$

Por tanto, para poder tener disponible el dinero necesario para 
la renovación de los equipos, se deben invertir el día de hoy .

" Búsqueda de la tasa de interés: Una persona quiere invertir el día de hoy $\$ 50.000 .000$ en un fondo de inversiones de forma que cuando estime llegue su momento de jubilación (dentro de 20 años) pueda disponer de $\$ 120.000 .000$, ¿a qué tasa anual debería rendir este fondo para permitir acumular esta cantidad de dinero?

$$
\begin{aligned}
& V P=\$ 50.000 .000 \\
& V F=\$ 120.000 .000 \\
& n=20 \\
& i=(V F / V P)^{(1 / n)}-1 \\
& i=(120.000 .000 / 50.000 .000)^{1 / 2} \\
& -1=4,4746 \% \text { anual }
\end{aligned}
$$

Es decir, el fondo debería rentar en promedio el $4,4746 \%$ anual para poder acumular la cantidad de dinero indicada al final de 20 años.

"Búsqueda de la duración de la operación: Para el ejemplo anterior, si la tasa de interés disminuye al 2,5\% anual, ¿Cuánto tiempo debe pasar para que los $\$ 50.000 .000$ se conviertan en $\$ 120.000 .000$ si permanecen en dicho fondo?

$V P=\$ 50.000 .000$

$V F=\$ 120.000 .000$

$i=2,5 \%$ anual

$n=\log V F-\log V P / \log (1+i)$

$\mathrm{n}=\log (120.000 .000)$

$-\log (50.000 .000) /$

$\log (1+2,5 \%)=35,5$ años

Deben transcurrir aproximadamente 35 años $^{5}$ y medio para lograr acumular la cantidad de dinero esperada.

5. Tener en cuenta que el resultado de la ecuación dará en la misma periodicidad que esté expresada la tasa de interés. En este caso, como la tasa de interés está expresada de manera anual, el tiempo también se expresará en años. 


\section{LA TASA DE INTERÉS}

Hasta este punto se han trabajado los conceptos y casos presentados, partiendo del hecho de que no deben transformarse las tasas de interés. Sin embargo, como podrá constatar el lector, no siempre este es el caso que se presenta en el entorno de los negocios. Por ejemplo, ¿cómo se puede comparar una alternativa de inversión cuya rentabilidad está expresada en una tasa mensual y otra que esta expresada en términos anuales? En este contexto es muy importante entender cómo la periodicidad de la tasa afecta los valores obtenidos cuando se están evaluando equivalencias de dinero en el tiempo.

En términos generales, una tasa de interés puede expresarse de tres formas diferentes:

Forma 1: Como tasa nominal: la palabra nominal viene de nombre; cuando la tasa de interés se expresa de esta forma, se asocia con el concepto de interés simple (es decir, cuando no hay variación del capital), por lo que en el contexto de interés compuesto solamente es de referencia y no puede emplearse directamente para hacer operaciones. Esta tasa de interés normalmente se expresa en términos anuales y debe estar acompañada de su "frecuencia" de capitalización. Por ejemplo: 24\% Nominal Anual Mes Vencido (NAMV); 35\% Nominal Anual Trimestre Vencido (NATV).

Pero ¿qué es la frecuencia de capitalización? Este término, guarda relación con el número de veces que los intereses se capitalizan, es decir, "se vuelven capital” en un período de un año. Entonces, si se tiene una tasa del $24 \%$ NAMV, se estaría diciendo que cada mes una fracción de esta tasa se "convierte” en capital, pero ¿cuál fracción? Para responder a esta pregunta, es necesario observar la siguiente forma de expresar la tasa de interés.

Forma 2: Tasa periódica: surge de dividir la tasa nominal entre la frecuencia de capitalización indicada. Siguiendo con los anteriores ejemplos, la tasa periódica correspondiente a una Tasa Nominal Anual Mes Vencido, será la que resulta de dividir dicha tasa entre 12 (porque hay 12 meses en 
un año). Entonces, la tasa de interés mes vencido (periódica) correspondiente a una tasa del 24\% NAMV será del $24 \% / 12=2 \%$ (mes vencido) ${ }^{6}$. Es decir, que el $2 \%$ es la porción de los intereses que mes a mes se capitaliza. Y dado que se da este proceso de capitalización, surge, por tanto, otra forma de expresar la tasa de interés: la tasa efectiva anual.

Forma 3: La tasa efectiva anual, se da como resultado del proceso de acumulación de intereses que se da en la modalidad de interés compuesto y hace que el capital sobre el que estos son calculados cambie período a período. Un ejemplo ayudará a clarificar esta situación: imagine el lector que tiene la oportunidad de invertir $\$ 1.000 .000$, en un fondo de inversión que reconoce una tasa del $12 \%$ NATV, esto quiere decir, que cada trimestre se aplicará una tasa del $3 \%$ al capital acumulado. Usted espera permane- cer en el fondo por un año, y retirará los intereses y el capital al final de este período. Por tanto,

En el primer trimestre se tendría por concepto de interés: $\$ 1.000 .000 * 3 \%$ $=\$ 30.000$

Si no se retiran los rendimientos ganados, estos se convierten en capital, por lo que los intereses del segundo trimestre serán: $\$ 1.030 .000 * 3 \%=30.900$. Esta operación se repite trimestre a trimestre de la siguiente forma:

6. Los términos vencidos y anticipados hacen referencia al momento en el que se calculan los intereses, si es al inicio o al final del período (ya sea del mes, del trimestre, semestre, etc.). En el caso primero serán anticipados y en el caso del último, serán vencidos. Los intereses vencidos son los de mayor utilización en el contexto de los negocios, por lo que se deja al lector en libertad de indagar más sobre las implicaciones de los intereses anticipados. 


\section{TABLA 3}

\section{ACUMULACIÓN DE INTERESES MEDIANTE LA MODALIDAD DE INTERÉS COMPUESTO}

Fuente: Elaboración propia

\begin{tabular}{|c|c|c|}
\hline Trimestre & $\begin{array}{c}\text { Saldo al iniciar } \\
\text { el trimestre }\end{array}$ & Intereses \\
\hline
\end{tabular}
1
1.000 .000
30.000
1.030 .000

2

1.030 .000

30.900

1.060 .900

3

1.060 .900

31.827

1.092 .727

4 
Los intereses acumulados en toda la operación ascienden a 125.509 (diferencia entre 1.125 .509 y 1.000 .000 ), que en términos porcentuales representan el 12,55\% (125.509/1.000.000) y que se conoce como Tasa Efectiva Anual (EA). Por tanto, se observa que la tasa que se logra en un año es superior a la simple suma aritmética de la tasa de interés trimestral.

\section{PARA TENER EN CUENTA:}

Si bien, de acuerdo con la normatividad colombiana, las instituciones financieras están obligadas a indicar cuál es la tasa efectiva anual que se cobra (en el caso de un crédito) o que se genera (en el caso de una inversión), no olvide nunca, al momento de realizar una operación financiera, estar enterado de esta variable ya que esta indicará el costo o la rentabilidad real del producto.

La tasa de interés EA, será mayor en la medida en que la frecuencia de capitalización sea más alta; se invita al lector a comprobar este resultado, reproduciendo el anterior cuadro teniendo en cuenta una tasa del $12 \%$ nominal anual mes vencido, la misma inversión inicial y el mismo plazo de un año. Este resultado se da como consecuencia de que los intereses se convierten en capital un mayor número de veces en el año. El dominio de este concepto es fundamental ya que ésta es la tasa a la que se deben expresar los productos financieros de deuda y de inversión a los que normalmente tiene acceso una MIPYME (ver recuadro anterior). 


\title{
CASO DE ESTUDIO:
}

\author{
¿CUÁL ES EL COSTO REAL DE NO \\ APROVECHAR LOS DESCUENTOS \\ POR PRONTO PAGO QUE \\ OFRECEN LOS PROVEEDORES?
}

Es importante habituarse a la idea de que, en un negocio, uno de los costos financieros más altos que se puede enfrentar es el desaprovechamiento de los descuentos por pronto pago. El ofrecimiento de crédito a los clientes es una realidad en el entorno competitivo de los negocios, sin embargo, la necesidad de liquidez también lo es. Por tanto, en muchos casos, los proveedores, con el fin de recuperar su cartera de la forma más rápida posible, ofrecen descuentos por pronto pago que muchas veces no se aprovechan bajo la noción equivocada de que la financiación con proveedores no tiene costo, así que i¿para qué pagar antes?! Sin embargo, como se tratará de ilustrar con el siguiente caso, la situación es otra:
Una empresa de implementos para oficina y colegios hace una compra de mercancía para venta por valor de $\$ 15.000 .000$, su proveedor le otorga para su pago un plazo de 30 días. Sin embargo, también le ofrece la opción de otorgarle un descuento por pronto pago del 3\% del valor de la factura si la paga el día 10, si no, puede pagar el 100\% del valor el día 30.

Primero, se debe conocer cuál sería el valor de la factura con descuento, que sería: $15.000 .000 *(1-3 \%)=14.550 .000$.

Segundo, se debe determinar cuál es la tasa de interés que convierte 14.550 .000 en 15.000 .000 transcurridos 20 días 



\section{LAS CINCO C DEL CRÉDITO Y EL ACCESO A FINANCIACIÓN:}

En la gran mayoría de los casos, los productos financieros utilizados por las PYMES están relacionados con productos de crédito (exceptuando las cuentas de ahorro y corrientes). Por lo tanto, es muy importante, no sólo conocer acerca de los costos efectivos de este tipo de operaciones sino de aspectos relacionados con variables que determinan las condiciones en que las empresas pueden acceder a financiación. En este sentido, de acuerdo con los principios básicos de la teoría para un análisis de crédito, se deben contemplar como mínimo diferentes elementos fundamentales, conocidos como las cinco C del crédito (Morales \& Morales, 2014), (Pampillón, de la Cuesta, Ruza, Vázquez, \& Bustarviejo, 2017), así:

\section{Carácter: Corresponde al compor-} tamiento o hábito de pago y al historial crediticio del cliente. Ante un buen comportamiento en el pago de las obligaciones, se genera una mayor probabilidad de que la enti- dad financiera le otorgue el préstamo solicitado. Este comportamiento se puede validar con fuentes de información interna y externa (consultas a las centrales de riesgo) en donde se observa la trazabilidad de las obligaciones, el monto de cada una de ellas, la periodicidad del pago, el valor de las cuotas, si ha presentado mora en el pago de estas o han sido atendidas oportunamente y las garantías ofrecidas. Las entidades financieras pueden emplear métodos estadísticos que asignan puntajes y permiten predecir la viabilidad de la operación, la calidad del deudor, la probabilidad de incumplimiento, para de esta forma, de acuerdo con el puntaje obtenido, aprobar o rechazar la solicitud.

\section{Capacidad: Se establece cuál es} la fuente de los flujos de caja que permitan determinar su capacidad de pago y la periodicidad en la generación de efectivo. En el caso de las empresas, es importante identificar si los flujos de efectivo son constantes, como en el caso de una comercializadora, 
por cuanto compran el producto terminado y lo venden (generalmente sin ninguna transformación), al consumidor final, lo cual les permite un mayor volumen de recursos (flujo de caja) en el corto plazo, o si los flujos corresponden a periodos más largos, por ejemplo las empresas manufactureras. Éstas requieren de un proceso que inicia desde la compra de la materia prima y que pasa por la transformación, elaboración del producto y la venta (en muchos casos a intermediarios), lo cual demanda mayor tiempo y por lo tanto no se cuenta con la misma liquidez que las empresas comercializadoras. De ahí que cuando se otorgue el crédito, la frecuencia en el pago de las cuotas deba corresponder con la generación del flujo de efectivo de las empresas para evitar que incumplan sus compromisos. Es necesario revisar el endeudamiento actual y futuro de acuerdo con el nuevo préstamo, ya q que entre menor sea la relación deuda/ingreso, mayor es la capacidad de pago que tiene el solicitante del crédito.
3. Capital: corresponde al aporte realizado por los socios o accionistas; a mayor capital presentado por la empresa, mayor compromiso de los propietarios, lo cual es un buen indicador para los bancos a la hora de realizar el análisis de crédito. Si la participación del capital con relación al activo de la empresa es alta, es un indicador de bajo endeudamiento y más equilibrio en su estructura financiera. Ahora bien, existen empresas que por su dinámica y por el sector donde llevan a cabo sus actividades, la estructura de financiación puede estar más comprometida con terceros (pasivos) y por lo tanto requieren de mayor apalancamiento.

4. Colateral: corresponde a la garantía ofrecida o exigida por el establecimiento bancario; una garantía idónea que tenga un buen margen de cobertura, le da mayor peso en el análisis de crédito y permite mejorar las condiciones financieras del crédito. Actualmente existen en el sistema financiero múltiples garantías que flexibilizan el otorgamiento de crédito y permiten a 
las entidades financieras recuperar parcial o totalmente la deuda en caso de no pago por incumplimiento del deudor. Se puede considerar como una segunda fuente de recuperación del crédito, y no implica que si el cliente ofrece una excelente garantía y con un margen de cobertura muy amplio (de 3 o más veces al monto solicitado) el banco esté obligado a otorgar el préstamo. Las garantías se consideran como reales cuando recaen sobre bienes muebles o inmuebles (por ejemplo una hipoteca) o también se conocen como avales cuando éstas recaen sobre las personas (codeudores).

\section{Condiciones: se refiere al destino} del crédito, a qué sector económico se dirigen los recursos, si corresponde a un sector que está en dificultades o se prevé una recesión es muy probable que los bancos sean más cautelosos en el análisis de crédito. Por el contrario, si corresponde a un sector que presenta auge y crecimiento es más factible que se apruebe el crédito. No obstante, se pueden presentar empresas que se encuentran en sectores con dificultades, pero con excelentes indicadores y variables positivas cuyo resultado es la aprobación del crédito. De otra parte, se puede presentar empresas con indicadores negativos en sectores con bastante dinamismo y crecimiento, lo cual no las hace sujetos de crédito. Como en la economía se presentan periodos de recesión y expansión, sin determinar la extensión en tiempo ni la profundidad de éstas, se establece que los sectores que correspondan a los bienes de capital están directamente relacionados con estos ciclos, mientras que sectores que atienden o cubren necesidades básicas están menos expuestos. Por lo tanto, un buen análisis de crédito contempla diferentes escenarios y la exposición al riesgo de crédito que asume la entidad financiera.

El empresario deber ser consciente de que el negocio de un banco es prestar dinero y saber que, si las medidas adoptadas por el departamento de crédito son muy rigurosas y exigentes los efectos se pueden reflejar 
en el menor volumen de operaciones tramitadas, aprobadas y, por lo tanto, menores ingresos para los bancos. Si por el contrario, se adoptan medidas laxas y con pocos criterios, el volumen de operaciones aprobadas se incrementará, lo cual genera en el corto plazo mayores ingresos, pero en el mediano o largo plazo las consecuencias por pérdidas (no pago de los créditos) serán mayores; de ahí que el departamento debe ser lo más eficiente, pero a la vez lo más rentable con bajo riesgo.

\section{FACTORING: UNA ALTERNATIVA DE FINANCIACIÓN DIFERENTE AL CRÉDITO}

Uno de los mayores problemas que se presenta en las micro y pequeñas empresas está relacionado con la disponibilidad de efectivo para atender las necesidades diarias de la operación, tales como pago de nómina, dilación en el pago a proveedores, pago de servicios públicos, arriendo, entre otros (riesgo de liquidez), lo cual dificulta el margen de maniobra y puede afectar el normal funcio- namiento de la organización. De ahí que sea necesario adoptar medidas y mecanismos que minimicen este riesgo. Para tal efecto, el factoring ofrece otra alternativa para la obtención de recursos para las empresas, además de los productos de crédito tradicionales ofrecidos por las entidades financieras (cartera ordinaria, sobregiro, cupos rotativos entre otros).

Como un mecanismo para obtener liquidez, el factoring consiste en la transformación anticipada de las cuentas por cobrar que los clientes tienen con la empresa en efectivo para, de esta forma, obtener los recursos líquidos necesarios para la operación. Esta alternativa le permite a las Mipymes continuar con sus actividades misionales sin necesidad de acudir a fuentes de financiación que en muchos casos no son fáciles de conseguir, dado el nivel de riesgo, de condiciones, requisitos y garantías exigidas por parte de las entidades financieras.

En estas operaciones el acreedor, la empresa, cede la factura a favor de un tercero (denominado factor), que puede ser una entidad financiera, quien le 
pagará a la empresa y a la vez se hará cargo de la gestión de cobro. El factor puede o no asumir el riesgo ante el incumplimiento del pago del deudor al vencimiento del plazo de la factura. Entonces, se denomina factoring con recurso, cuando la empresa que expide la factura por la venta de un producto o servicio asume el pago de la factura ante el vencimiento de ésta y el deudor incumple en el pago de la obligación, exonerando a la entidad financiera del riesgo de no pago del cliente; en este tipo de operaciones, es la misma empresa que expide la factura quien asume el riesgo. Por su parte, el factoring sin recurso, en este caso la entidad financiera - la empresa factor, es quien asume el riesgo ante el incumplimiento en el pago de la factura por parte del deu- dor al vencimiento de esta. Actualmente algunas entidades financieras ofrecen los dos tipos de contrato, una vez analizadas las empresas que emiten las facturas y las empresas deudoras de dichas facturas. Esta fuente de financiación adquirió mayor fuerza en Colombia a partir de la expedición de la ley 1231 de 2008, que simplificó los requisitos para que las facturas puedan ser consideradas como títulos valores facilitando su negociación.

A manera de ejemplo, se presenta una operación de factoring asumida por una entidad financiera así:

Valor de la Factura $\$ 30.000 .000$

Porcentaje de reserva

$15 \% \$ 4.500 .000^{7}$ 
Valor de la factura al

$85 \% \$ 25.500 .000$

Plazo de la factura 30 días

Año base 360 días

Tasa efectiva anual $11.80 \%$

Al aplicar la fórmula de valor presente,

$$
\begin{aligned}
& \mathrm{VP}=\$ 25.500 .000 / \\
& (1+11, .80 \%)^{(30 / 360)}=\$ 25.264 .073
\end{aligned}
$$

Por lo tanto, al valor de la negociación de la factura se resta el valor presente y arroja el descuento

Valor descuento $=\$ 25.500 .000$

- $\$ 25.264 .073=235.927$

Valor descuento $\$ 235.927$

Valor neto a entrega $\$ 25.264 .073$

Las condiciones en cuanto a tasa, porcentaje de reserva y año base, pueden variar de una entidad a otra.
En este ejercicio la empresa recibe a la fecha de la negociación \$25.264.074 y al cabo de los 30 días siguientes recibirá $\$ 4.500 .000$, por lo tanto, el costo asumido es de $\$ 235.927$, a cambio de ello la organización obtiene recursos para atender sus necesidades operacionales sin tener contratiempos en el flujo de caja. 